\title{
HEDONIC SHOPPING MOTIVATIONS IN COLLECTIVISTIC AND INDIVIDUALISTIC CONSUMER CULTURES
}

Heiner Evanschitzky* Professor of Marketing, Aston Business School, Marketing Group, Aston Triangle, Birmingham, B4 7ET, UK (h.evanschitzky@aston.ac.uk)

Oliver Emrich (Assistant Professor of Distribution Management and E-Commerce. University of St.Gallen, Institute of Retail Management, Dufourstrasse 40a, CH-9000 St.Gallen. oliver.emrich@unisg.ch)

Vinita Sangtani (Assistant Professor of Marketing. Mike Cottrell School of Business, North Georgia College and State University. vsangtani@ northgeorgia.edu__

Anna-Lena Ackfeldt (Lecturer in Marketing . Aston Business School, Marketing Group, Aston Triangle, Birmingham, B4 7ET, UK. a.ackfeldt@ aston.ac.uk )

Kristy E. Reynolds (Bruno Associate Professor of Marketing. Department of Management and Marketing, Culverhouse College of Commerce, The University of Alabama. kreynold@cba.ua.edu)

Mark J. Arnold (Senior Associate Dean, Professor of Marketing. Department of Marketing, John Cook School of Business, Saint Louis University. arnoldm2@slu.edu )

*) corresponding author

\section{ARTICLE INFO}

\section{Article history:}

First received in October 10, 2013 and was under review for 41/2 months.

Replication Editor: John G. Lynch 


\section{HEDONIC SHOPPING MOTIVATIONS IN COLLECTIVISTIC AND INDIVIDUALISTIC CONSUMER CULTURES}

We reinvestigate what constitutes hedonic customer experiences in collectivistic versus individualistic cultures using four country samples $(\mathrm{N}=2,336)$ in Germany and the U.S. as well as Oman and India. Across country samples, intrinsically enjoyable customer experiences are associated with the same underlying hedonic shopping motivations as shown in the original U.S. context. In comparison with individualistic cultures, we find that a hedonic shopping experience in collectivistic cultures is less strongly associated with selforiented gratification shopping, yet more strongly associated with others-oriented role shopping. 


\section{Motivation for the Study}

Although a rich body of literature investigates customer experiences from a hedonic versus utilitarian perspective, little research has examined the cross-cultural variation in what constitutes hedonic experiences in a retail setting, and the underlying hedonic shopping motivations consumers have in different cultures. Replicating Arnold and Reynolds' (2003) data in the U.S. in three countries, we investigate if intrinsically enjoyable customer experiences in collectivistic societies are driven by the same hedonic shopping motivations as in individualistic societies.

\section{Expected Cultural Differences}

Hedonic shopping experiences are deemed as a critical component for companies to differentiate themselves in in Eastern markets, emphasizing the relevance of research on culturally-influenced drivers of hedonic shopping (see Web-Appendix 1). Hedonic shopping motivations consist of six shopping dimensions (Arnold \& Reynolds, 2003): adventure, gratification, idea, role, social, and value. These six hedonic shopping motivations mediate the link between fundamental drivers within the goal system hierarchy, which are likely to be universal across cultures, and enjoyable shopping outcomes (Arnold \& Reynolds, 2012). Therefore, we expect that all hedonic shopping motivations are cross-culturally relevant for the customer experience.

H1: In individualistic consumer cultures (i.e., USA, Germany), intrinsically enjoyable customer experiences are associated with all hedonic shopping motivations.

H2: In collectivistic consumer cultures (i.e. India, Oman), intrinsically enjoyable customer experiences are associated with all hedonic shopping motivations.

However, important differences may arise in the weighting of these hedonic shopping motivations for the customer experience. In the U.S., Arnold and Reynolds (2003) found that intrinsically enjoyable customer experiences are particularly strongly associated with 
adventure and gratification shopping. Especially the link to gratification shopping may be stronger in individualistic than in collective cultures because gratification shopping serves personal goals which are more pronounced in individualistic cultures (Singelis, 1994). In contrast, consumers in collectivistic cultures less often feel the right to engage in selfgratification, but feel obliged to more strongly aim at maintaining groups' resources, relationships, and mutual obligations such as inherent in role shopping (Triandis, McCusker, \& Harry, 1990).

H3: In collectivistic cultures, the association of intrinsically enjoyable customer experiences with gratification shopping is weaker, and the association with role shopping is stronger than in individualistic cultures.

In cross-cultural comparisons, attention must be devoted to the reflective measurement; that is, whether the different weighting of hedonic motivations is real or results only from differences in the mapping of underlying latent constructs (Steenkamp \& Baumgartner, 1998). Moreover, differences in income between Western and Eastern markets may bias the association of hedonic shopping motivations with intrinsically enjoyable experiences.

\section{H4: $\quad$ Cross-cultural differences in the weighting of hedonic shopping motivations for} intrinsically enjoyable customer experiences are not confounded by differences in reflective measurement or in income.

\section{Method and Samples ${ }^{1}$}

We conducted studies in two individualistic countries (U.S. and Germany) and in two collectivistic countries (India and Oman) retaining the original US data (Table 1). In line with Arnold and Reynolds (2003), we use hedonic shopping motivations (7-point Likert scales ranging from 1 = "Strongly Disagree" to 7 = "Strongly Agree") as independent variables and measure intrinsically enjoyable customer experiences as outcomes by the flow scale (7-point 
Likert scale from 1 = "Strongly Disagree" to 7 = "Strongly Agree"; Bloch et al., 1994). Among socio-demographic measures, income levels vary significantly between countries so we compute a four level relative income variable that approximately divides respondents into quartiles of the income distribution for each country sample (coded 1 for the lowest income class and 4 for the highest income class). As an indicator for collective orientation, the generosity scale (7-point Likert scale from 1="Strongly Disagree" to 7="Strongly Agree"; Belk, 1985) validates that collectivistic country samples have a significantly higher generosity score than individualistic country samples (India and Oman: 4.88; U.S. and Germany: 4.68, $t=4.60, p<.05)$.

\section{Findings}

Regarding H1 and H2, we separately test path coefficients between each hedonic shopping motivation and flow in all country samples. Because the flow construct is operationalized as one item assessing the overall shopping flow experience and three items that reflect flow based on distorted time perceptions, the model considers covariance between residual errors of the three related items. For all country samples, we find that each hedonic shopping motivation is positively associated with flow, replicating Arnold and Reynolds (2003) finding for the U.S. (see Web-Appendix 2). Confirming $\mathrm{H} 1$ and $\mathrm{H} 2$, the conceptualization of six hedonic shopping motivations is relevant to investigate hedonic shopping experiences across cultures. However, as posited in H3, cross-cultural differences may occur regarding the relative strength of associations which we will investigate next.

The comparison of relationships between constructs across cultures requires partial metric invariance which is provided if at least one indicator besides the marker item for each construct has invariant (i.e., equivalent) factor loadings across cultures (Steenkamp \& Baumgartner, 1998). We specify a model with at least two factor loadings per construct that are held equal across samples while not constraining the remaining (non-invariant) items. This 
partial mediation model results in 14 out of 22 factor loadings that are fixed (Web-Appendix 3). Using chi-square difference testing, the partial metric invariance model is compared with a model where all factor loadings are free across samples (Byrne, Shavelson, \& Muthén, 1989). Across all country samples, the partial metric invariance model did not differ significantly from the model with free factor loadings $\left(\Delta \chi_{27}^{2}=36.34\right.$, n.s. $)$, confirming partial metric invariance (see Appendix 1). We also successfully performed invariance models for the pooled individualistic and collectivistic samples (see Web-Appendix 4).

To test H3, we simultaneously examine the path coefficients of hedonic shopping motivations on flow in a multi-group model with pooled samples for individualistic cultures (U.S. and Germany) and collectivistic cultures (India and Oman) (see Table 2). At first, we assess stepwise for each path if coefficients significantly differ between individualistic and collectivistic cultures. We compare a model where all paths are free across samples with six models in which one path of interest is fixed, respectively. Significant differences in chisquare indicate that paths differ between individual and collectivistic cultures. In line with H3, we find that the association of gratification shopping with flow is stronger in individualistic than in collectivistic cultures $\left(\Delta \chi^{2}{ }_{1}=24.32, p<.05\right)$. In collectivistic cultures, stronger associations with flow are indicated for role shopping $\left(\Delta \chi^{2}{ }_{1}=5.77, p<.05\right)$, adventure shopping $\left(\Delta \chi_{1}^{2}=5.91, p<.05\right)$, and value shopping $\left(\Delta \chi^{2}{ }_{1}=7.04, p<.05\right)$, compared with individualistic cultures.

To test H4, we assess interaction effects between hedonic shopping motivations and cultural differences. ${ }^{2}$ Model 1 shows significant associations between all six hedonic shopping motivations (operationalized as average scores) and flow, even when controlling for cultural difference (coded as 1 for collectivistic cultures and 0 for individualistic cultures) and income (see Table 3). Model 2, with interaction terms between cultural difference and hedonic shopping motivations as well as income, provides support for the hypothesized

\footnotetext{
${ }^{2}$ Additional invariance tests for multi-group comparisons are included in the Web-Appendix.
} 
cultural differences in the association of gratification and role shopping with flow. For collectivistic cultures, the association between flow and gratification shopping is weaker $(\beta=-$ $.19, t=-5.07, p<.05)$, and the association between flow and role shopping is stronger $(\beta=.10$, $t=2.92, p<.05$ ), compared with individualistic cultures. These results remain robust if including interactions between hedonic shopping motivations and income (Model 3), and if considering three way interactions between hedonic shopping motivations, cultural difference, and income (Spiller, Fitzsimons, Lynch, \& McClelland, 2013; see Web-Appendix 6).

In summary, we can rule out that findings for $\mathrm{H} 3$ are caused by reflective measurement differences or are confounded by differences in income.

\section{-Tables 2 \& 3}

\section{Discussion}

Our findings suggest that the association between intrinsically enjoyable customer experiences and hedonic shopping motivations varies significantly between cultures. While we can replicate in a cross-cultural context that all shopping motivations are relevant for hedonic experiences, major differences occur with regards to the significance of gratification and role shopping in individualistic versus collectivistic cultures. In individualistic cultures, shopping is intrinsically most enjoyable if gratification (or adventure) shopping motivations are underlying the customer experience. In collective cultures, it seems to be socially less accepted to gratify oneself through shopping, making gratification shopping less appealing. In contrast, role shopping is more strongly associated with intrinsically enjoyable customer experiences in collectivistic than in individualistic cultures. This supports that flow-like shopping experiences are more strongly promoted by self-oriented shopping motivations in individualistic cultures and by others-oriented shopping motivations in collectivistic cultures. 


\section{REFERENCES}

Arnold, M. J., \& Reynolds, K. E. (2003). Hedonic shopping motivations. Journal of Retailing, 79(2), 77-95. doi:10.1016/S0022-4359(03)00007-1

Arnold, M. J., \& Reynolds, K. E. (2012). Approach and Avoidance Motivation: Investigating Hedonic Consumption in a Retail Setting. Journal of Retailing, 88(3), 399-411. doi:10.1016/j.jretai.2011.12.004

Belk, R. W. (1985). Materialism: Trait Aspects of Living in the Material World. Journal of Consumer Research, 12(3), 265-280. doi:10.2307/254373

Bloch, P. H., Ridgway, N. M., \& Dawson, S. A. (1994). The shopping mall as consumer habitat. Journal of Retailing, 70(1), 23-42. doi:10.1016/0022-4359(94)90026-4

Byrne, B. M., Shavelson, R. J., \& Muthén, B. (1989). Testing for the equivalence of factor covariance and mean structures: The issue of partial measurement invariance. Psychological Bulletin, 105(3), 456-466. doi:10.1037/0033-2909.105.3.456

Hui, C. H., \& Triandis, H. C. (1986). Individualism-Collectivism A Study of Cross-Cultural Researchers. Journal of Cross-Cultural Psychology, 17(2), 225-248. doi:10.1177/0022002186017002006

Singelis, T. M. (1994). The Measurement of Independent and Interdependent Self-Construals. Personality and Social Psychology Bulletin, 20(5), 580-591. doi:10.1177/0146167294205014

Spiller, S. A., Fitzsimons, G. J., Lynch, J. G., \& McClelland, G. H. (2013). Spotlights, Floodlights, and the Magic Number Zero: Simple Effects Tests in Moderated Regression. Journal of Marketing Research, 50(2), 277-288. doi:10.1509/jmr.12.0420

Steenkamp, J. E. M., \& Baumgartner, H. (1998). Assessing Measurement Invariance in Cross-National Consumer Research. Journal of Consumer Research, 25(1), 78-107.

Triandis, H. C., McCusker, C., \& Harry, C. (1990). Multimethod probes of individualism and collectivism. Journal of Personality and Social Psychology, 59(5), 1006-1020. doi:10.1037/0022-3514.59.5.1006 


\section{TABLES}

Table 1

Sample characteristics

\begin{tabular}{lllll}
\hline Samples & $\begin{array}{l}\text { Individualism } \\
\text { score }^{\mathrm{a}}\end{array}$ & $\mathrm{N}$ & $\begin{array}{l}\text { Gender } \\
\text { (female) }\end{array}$ & $\begin{array}{l}\text { Age } \\
<36 \text { years) }\end{array}$ \\
\hline U.S. & 91 & 233 & $67 \%$ & $55 \%$ \\
Germany & 67 & 931 & $48 \%$ & $52 \%$ \\
India & 48 & 885 & $40 \%$ & $87 \%$ \\
Oman & 38 & 287 & $53 \%$ & $94 \%$ \\
\hline
\end{tabular}

${ }^{a}$ On Hofstede's individualism scale with scores of 91 and 67 representing highly individualistic and scores of 48 and 38 representing collectivistic consumer cultures (Hofstede center 2013). Oman was not explicitly investigated by Hofstede, but is supposed to have a very low individualism score between 25 for Arab emirates and 38 for other Arab countries (Hofstede center 2013). In India and Oman, the major share of population is below 36 years (India: 63\%) with a median age of 26.7 years in India and 24.7 years in Oman, which is even higher in urban areas, and a higher share of the male population (CIA 2013). Therefore, we deem the samples as a good representation of the overall population. 
Table 2

Two-group comparison test for equality of path coefficients

\begin{tabular}{|c|c|c|c|}
\hline & \multicolumn{2}{|c|}{ Simultaneous path assessment for each sample } & $\begin{array}{l}\text { Test of equality of path coefficients } \\
\text { between pooled samples }\end{array}$ \\
\hline & $\begin{array}{l}\text { Individualistic cultures } \\
\text { (U.S. and Germany) }\end{array}$ & $\begin{array}{l}\text { Collectivistic cultures } \\
\text { (India and Oman) }\end{array}$ & Individualistic versus collectivistic \\
\hline & $\beta$ (t-value) & $\beta(\mathrm{t}$-value $)$ & $\Delta \chi^{2}(1)$ \\
\hline ADV & $.29 *(4.35)$ & $.53 *(7.22)$ & $5.91 *$ \\
\hline GRA & $.29 *(5.59)$ & $-.04(-1.00)$ & $24.32 *$ \\
\hline IDE & $.18 *(5.12)$ & $.13 *(3.63)$ & .81 \\
\hline ROL & $.07(1.76)$ & $.20 *(4.94)$ & $5.77 *$ \\
\hline $\mathrm{SOC}$ & $.13 *(2.82)$ & $.07(1.40)$ & .83 \\
\hline VAL & $.08 *(2.69)$ & $.20 *(5.96)$ & $7.04 *$ \\
\hline
\end{tabular}

Note: Path coefficients were estimated for the individualistic and collectivistic samples in a two-group comparison model. For equality testing of regression coefficients, we subsequently constrained the path of interest to be equal across groups, and compared the chi-square difference to the model where all path coefficients are freely estimated. 
Table 3

Interactions of hedonic shopping motivations with cultural differences / income

\begin{tabular}{|c|c|c|c|}
\hline & \multicolumn{3}{|c|}{$\begin{array}{l}\text { Differences of collectivist versus individualist cultures } \\
\text { Cultural difference }(1=\text { collectivistic/0=individualistic) }\end{array}$} \\
\hline & Model 1 & Model 2 & Model 3 \\
\hline Adventure shopping (ADV) & $.22(10.78)^{*}$ & $.22(7.32)^{*}$ & $.17(3.26)^{*}$ \\
\hline Gratification shopping (GRA) & $.12(6.66)^{*}$ & $.23(8.03)^{*}$ & $.16(3.35)^{*}$ \\
\hline Idea shopping (IDE) & $.14(8.47)^{*}$ & $.17(6.99)^{*}$ & $.27(6.48)^{*}$ \\
\hline Role shopping (ROL) & $.10(5.94)^{*}$ & $.05(2.07)^{*}$ & $.11(2.57)^{*}$ \\
\hline Social shopping (SOC) & $.08(4.50)^{*}$ & $.10(3.99) *$ & $.11(2.44)^{*}$ \\
\hline Value shopping (VAL) & $.07(5.01)^{*}$ & $.06(2.91)^{*}$ & $.08(2.12)^{*}$ \\
\hline Cultural Difference (CUL) & $1.04(19.30)^{*}$ & $1.40(6.76)^{*}$ & $1.26(5.96)^{*}$ \\
\hline Income (INC) & $-.05(-2.80)^{*}$ & $-.10(-3.69)^{*}$ & $.01(.08)$ \\
\hline CULxINC & & $.11(2.81)^{*}$ & $.17(3.90)^{*}$ \\
\hline ADVxCUL & & $-.02(-.47)$ & $-.01(-.36)$ \\
\hline GRAxCUL & & $-.19(-5.07)^{*}$ & $-.19(-5.11)^{*}$ \\
\hline IDExCUL & & $-.06(-1.79)$ & $-.06(-1.74)$ \\
\hline ROLxCUL & & $.10(2.92)^{*}$ & $.09(2.79)^{*}$ \\
\hline SOCxCUL & & $-.06(-1.62)$ & $-.06(-1.72)$ \\
\hline VALxCUL & & $.03(.94)$ & $.03(.92)$ \\
\hline ADVxINC & & & $.02(.92)$ \\
\hline GRAxINC & & & $.03(2.09)^{*}$ \\
\hline IDExINC & & & $-.04(-2.89)^{*}$ \\
\hline ROLxINC & & & $-.02(-1.70)$ \\
\hline SOCXINC & & & $-.00(-.26)$ \\
\hline VALxINC & & & $-.01(-.70)$ \\
\hline $\mathrm{R}^{2}$ & .714 & .730 & .734 \\
\hline
\end{tabular}

Note: Unstandardized path coefficients are displayed. The models were calculated using average scores for hedonic shopping motivations. These results could be replicated using integration of latent factors based on a Monte Carlo simulation with 5,000 integration points (see Web-Appendix 6).

* p<.05 